\title{
The Appearance of an L1-like Molecule in the Chick Primary Visual Pathway
}

\author{
Vance Lemmon* and Steven C. McLoon† \\ *Department of Neurobiology, Anatomy and Cell Science and the Center for Neuroscience, University of \\ Pittsburgh, School of Medicine, Pittsburgh, Pennsylvania 15261, and †Department of Anatomy, University of \\ Minnesota, Minneapolis, Minnesota 55455
}

\begin{abstract}
A monoclonal antibody, 8D9, has been obtained that binds to axons in the chick nervous system. Biochemical and immunological experiments indicate that the 8D9 antigen is related to the mouse $\mathrm{L} 1$ cell-adhesion molecule. The results of immunohistochemical experiments using monoclonal antibody 8D9 to study the development of the chick visual system are consistent with the $8 D 9$ antigen functioning in axon fasciculation.
\end{abstract}

The development of the retinotectal projection has been a widely studied model system used in attempts to understand how axons find correct targets and how patterns of neuronal connections are established. Growing retinal axons select a very characteristic pathway in the retina and brain, enter only certain nuclei along the pathway, and synapse in specific locations within those nuclei. These selective events probably involve interactions between growing axons and their environment. Such interactions may be mediated by various cell-adhesion molecules. A number of different cell-adhesion molecules have been found in the chick visual system. These include Cognin (McClay and Moscona, 1974), neural cell adhesion molecule (N-CAM) (Thiery et al., 1977), N-Cadherin (Hatta et al., 1985), neuron-glial cell adhesion molecule (Ng-CAM) (Grumet and Edelman, 1984), L1 (Rathjen and Schachner, 1984), and a heparan sultate binding protein (Cole et al., 1985). There is also reason to suspect that other cell-adhesion molecules may be found in the chick visual system, as shown by preliminary work from other laboratories (Halfter et al., 1981; McClay, 1984). Since these different molecules were identified using in vitro cell-adhesion assays, it is important to study the developmental appearance of the molecules along the optic pathway, as well as in other parts of the nervous system, in order to identify possible functions of these molecules.

We have obtained a monoclonal antibody, $8 \mathrm{D} 9$, that binds to a cell-surface molecule, the 8D9 antigen, on chick retinal ganglion cells. Immunochemical studies indicate that the $8 \mathrm{D} 9$ antigen is related to the $\mathrm{L} 1$ cell-adhesion molecule. We have used this monoclonal antibody in combination with immunohistochemical techniques to follow the appearance and distribution of this antigen in the developing visual pathway. It was found that the 8D9 antigen was localized to axons of ganglion cells in a pattern consistent with its functioning in axon fasciculation. By virtue of its localization on optic axons, the 8D9

\footnotetext{
Received Dec. 19, 1985; revised Apr. 3, 1986; accepted Apr. 4, 1986.

We would like to thank J. Hailey and C. Snyder for technical assistance and C. Lagenaur for helpful suggestions. We are also grateful to F. Rathjen and U. Rutishauser for antiserum to L1. This work was supported by March of Dimes Grant 5-395 (V.L.) and National Eye Institute Grants 5285 (V.L.) and 5371 and 5372 (S.M.).

Correspondence should be addressed to Vance Lemmon, Ph.D., at the above address.

Copyright (C) 1986 Society for Neuroscience $0270-6474 / 86 / 102987-08 \$ 02.00 / 0$
}

antigen has proved very useful for studying the early pattern of optic axon growth in the brain. These studies have allowed us to demonstrate a substantial penetration of retinal axons into the cellular layers of the tectum early in development.

\section{Materials and Methods}

\section{Embryos}

Fertilized chicken eggs, either pathogen-free White Leghorn crossed with Rhode Island Red obtained from the University of Minnesota Poultry Center, or White Leghorn obtained from Sachs and Sons Poultry Farm, Evans City, PA, were incubated in a forced-draft incubator at $37^{\circ} \mathrm{C}$. For some experiments, after $3 \mathrm{~d}$ of incubation the eggs were removed from the shell and transferred to egg culture chambers (Dunn and Boone, 1976). The cultured embryos were maintained in a forced-draft tissue culture incubator at $37^{\circ} \mathrm{C}, 95 \%$ humidity, $1 \% \mathrm{CO}_{2}$. Embryos were staged according to Hamburger and Hamilton (1951).

\section{Immunizations and Fusions}

Optic nerves were dissected from 7 dozen embryonic day 14 (E14) chick embryos and homogenized in $5 \mathrm{ml}$ of Dulbecco's PBS. Mice were immunized with $0.1 \mathrm{ml}$ of homogenate at 4 week intervals followed by a series of 3 i.v. injections on successive days and removal of the spleen on the 4th day. Hybridomas were prepared with NS-1 myelomas using protocols described elsewhere (Kohler and Milstein, 1975; Lemmon et al., 1982). An immunohistochemical screening procedure was used to select for monoclonal antibodies that were specific for ganglion cells in the chick retina. After screening, positive wells were cloned and recloned by limiting dilution until over $90 \%$ of the clones were positive. Cell stocks were then frozen in liquid nitrogen.

\section{Screening and immunohistochemistry}

Retinas and optic tecta from E14 embryos were fixed with paraformaldehyde-lysine-periodate (PLP) (McLean and Nakane, 1974), cryoprotected with sucrose, and sectioned at $10-15 \mu \mathrm{m}$ in a cryostat. Hybridoma supernatants were incubated on the sections for $60 \mathrm{~min}$ at room temperature. The sections were then washed with PBS and incubated with a fluorescein-labeled goat anti-mouse-IgG (Cappel Labs) diluted 1:200 in PBS/10\% horse serum (HS). Sections were examined using a Leitz epifluorescence microscope.

Immunohistochemical analysis of the pattern of ingrowing ganglion cell axons was performed using monoclonal antibody 8D9. Cryostat sections of the developing visual pathway wcrc examined with an epifluorescence microscope. The stage of the microscope was equipped with potentiometers connected to an $X Y$ plotter in such a way as to allow the mapping and reconstruction of structures within the tissue being examined (see McLoon, 1985, for details of reconstruction).

\section{Electron-microscopic immunohistochemistry}

Eyes taken from embryos of various ages were fixed by immersion overnight at $4^{\circ} \mathrm{C}$ in PLP fixative. The eyes were then embedded in $2 \%$ agar and 1-2 mm sections were cut. The sections were blocked for $1 \mathrm{hr}$ with $\mathrm{PBS} / 10 \% \mathrm{HS}$ and then incubated with the primary antibody overnight at $4^{\circ} \mathrm{C}$ on a rocker. Next, the sections were washed 4 times with PBS over a $1 \mathrm{hr}$ period before being incubated with a biotin-labeled 

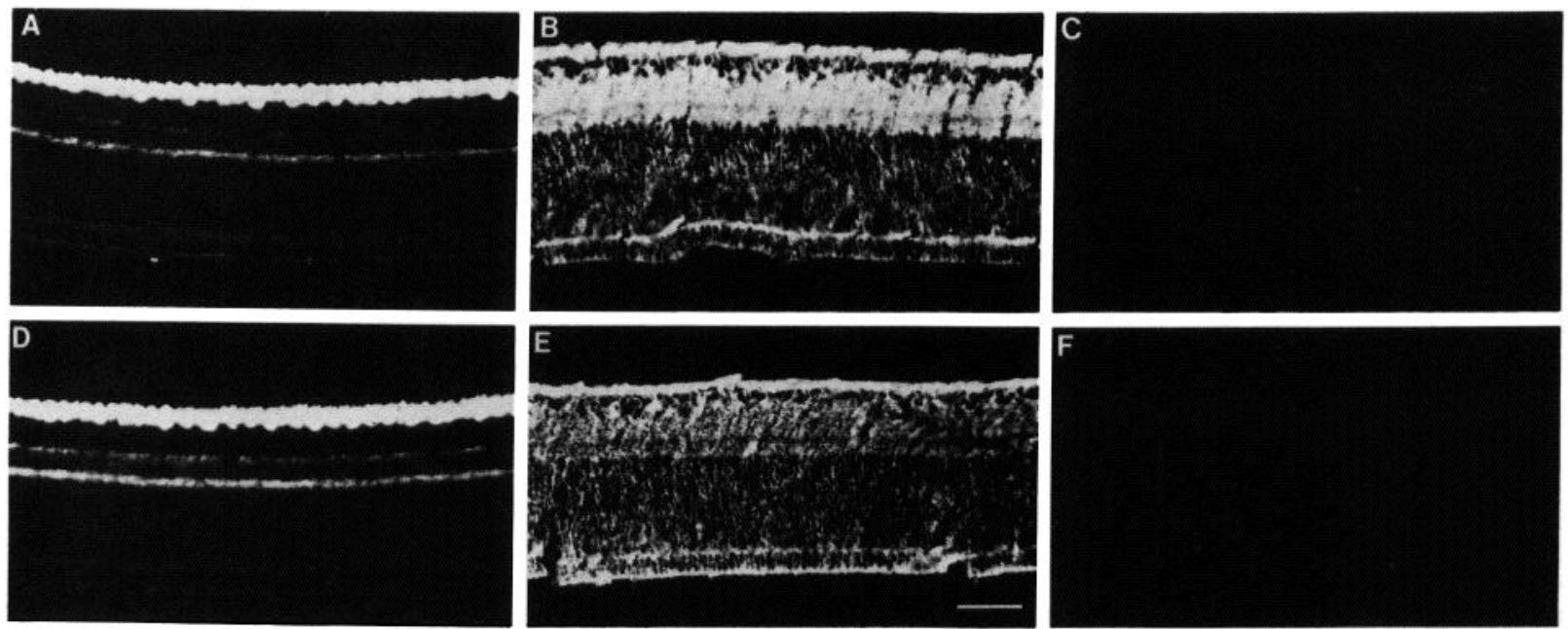

Figure 1. Immunohistochemical staining of E14 retina. A, Staining with monoclonal antibody 8D9. There is intense staining of the optic fiber layer at the top and faint staining of 2 bands in the inner plexiform layer. B, Staining with a monoclonal antibody against N-CAM (1A6) for comparison showing staining of the entire retina. $C$, Retina stained without primary antibody but with the FITC-labeled goat anti-mouse-IgG. $D$, Staining with rabbit anti-8D9 antigen antisera (1:1000 dilution). $E$, Staining with rabbit anti-1A6 antigen antisera (1:1000 dilution). $F$, No primary control with FITC-labeled goat anti-rabbit-IgG. Scale bar, $50 \mu \mathrm{m}$.

secondary antibody (Vectastain, Vector Labs) for $1 \mathrm{hr}$ at room temperature. The sections were again washed 4 times and then incubated with avidin-biotin-horseradish peroxidase (ABC) complex (Vectastain, Vector Labs). After a final series of washes, the sections were reacted with diaminobenzidine/cobalt chloride/nickel ammonium sulfate solution (Adams, 1981). In a separate series of experiments, a colloidal gold-labeled goat anti-mouse-IgG (Janssen Pharmaceutica) was used at a dilution of 1:4 to localize monoclonal antibody $8 \mathrm{D} 9$ binding in the retina. The sections were then postfixed with osmium, dehydrated, and embedded in Epon 812 . Gold-colored sections were cut and examined using a Philips 300 EM.

\section{Immunohistochemical controls}

It is not possible to perform absorption controls using antigen in immunohistochemical studies with monoclonal antibodies to unknown
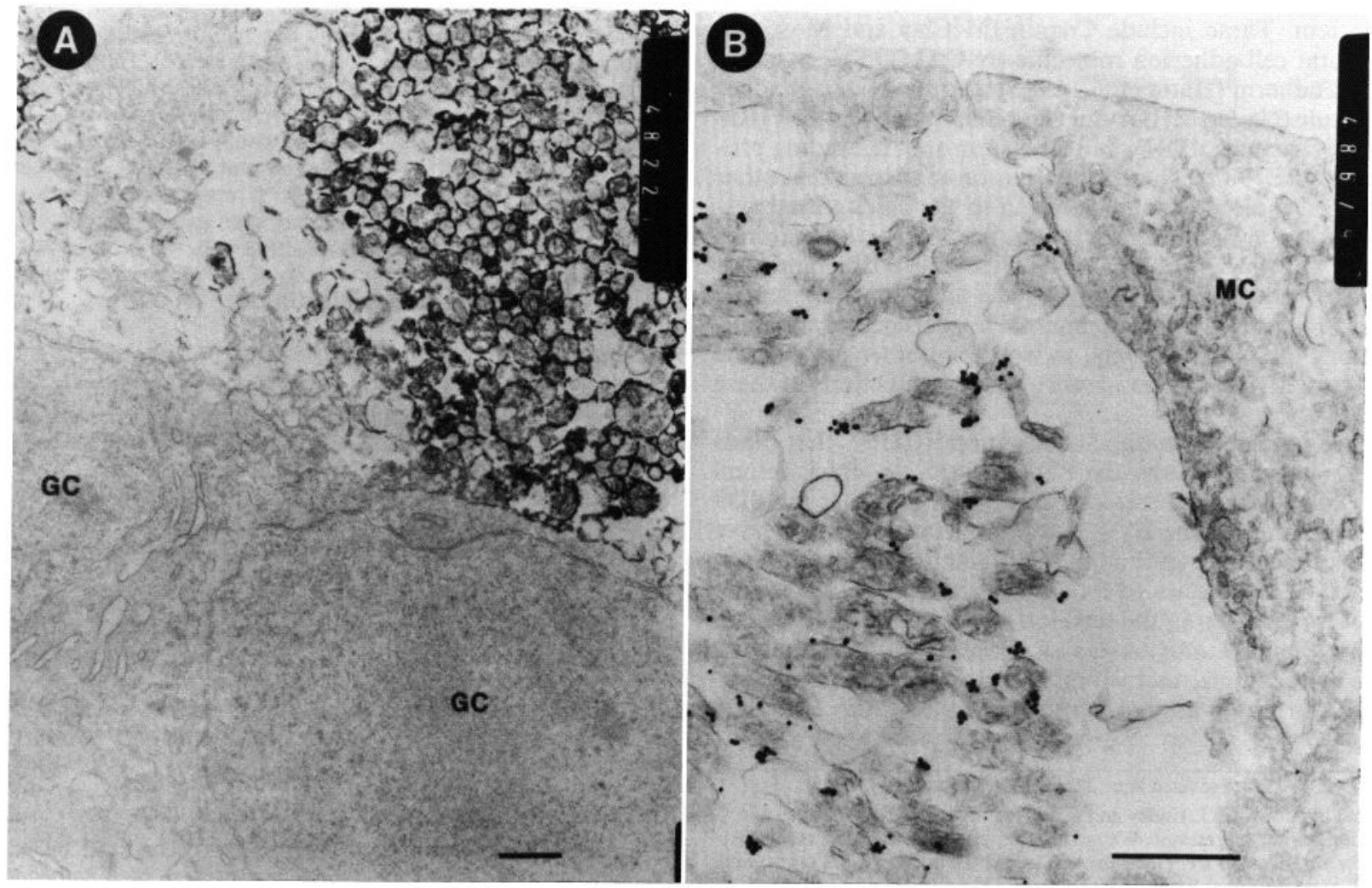

Figure 2. EM immunohistochemistry of E14 retina with monoclonal antibody 8D9. A, Using DAB and the Vectastain-HRP secondary system, the axons in the OFL were stained while the surface of ganglion cells $(G C)$ showed no label. Scale bar, $1 \mu \mathrm{m}$. $B$, Using gold-labeled secondary antibodies the external surfaces of axons were labeled, while adjacent Muller cell end-feet $(M C)$ were not labeled. Scale bar, $1 \mu \mathrm{m}$. 
$1 \mathrm{~A} 6$

8D9

\section{$\begin{array}{lllllllllllllll}4 & 5 & 6 & 7 & 8 & 9 & 10 & 11 & 4 & 5 & 6 & 7 & 8 & 9 & 10\end{array}$}

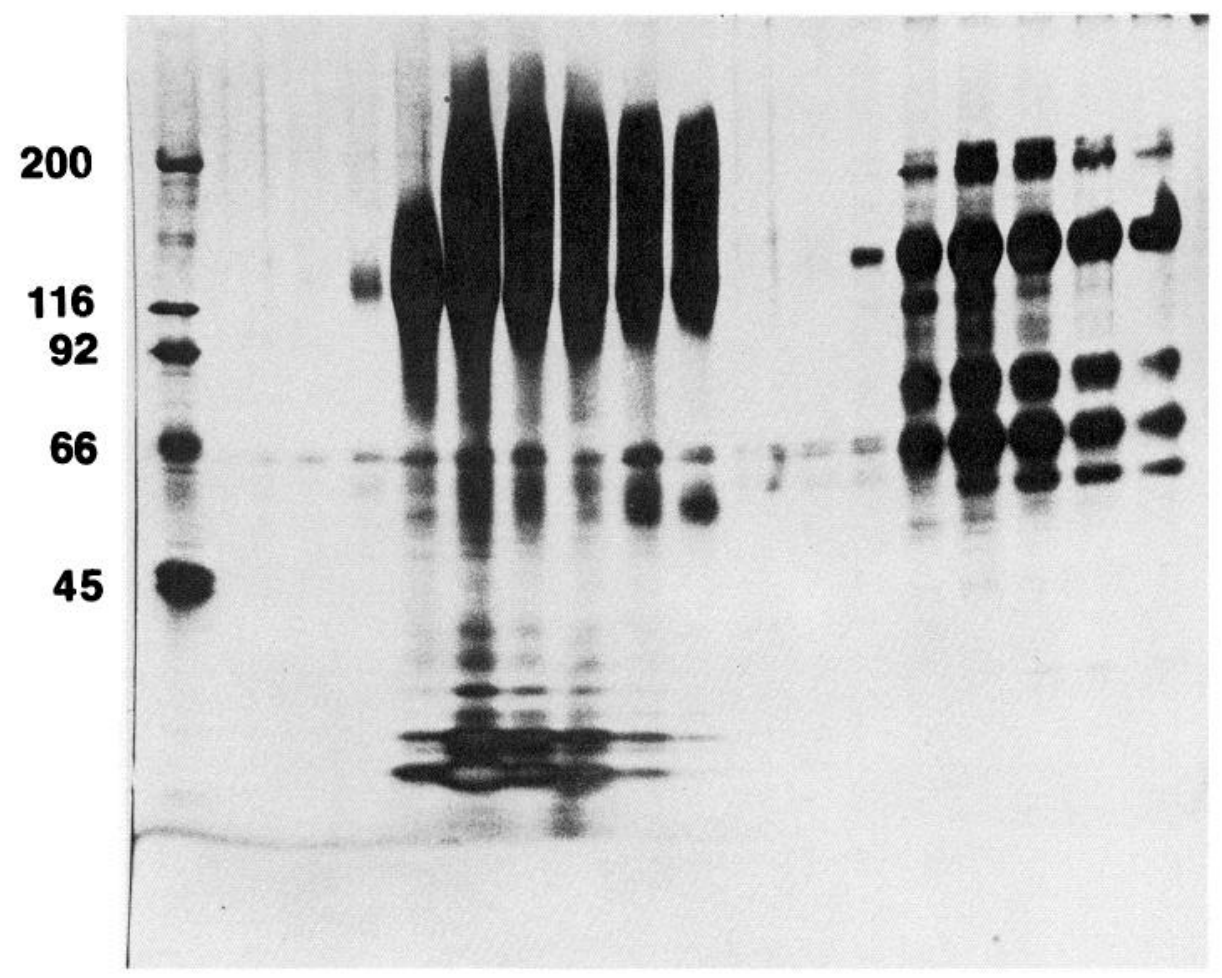

Figure 3. Affinity purification of antigens from Triton X-100 extracts of E19 chick brain membranes. Affinity column eluate fractions were run on $5-15 \%$ gradient SDS-PAGE and stained with silver. Fractions 4-11 from the $1 \mathrm{~A} 6$ column show the broad band expected for N-CAM. The 8D9 column eluate showed 4 major bands with molecular weights of about 190 , 135,83 , and $66 \mathrm{kDa}$. Molecularweight standards are shown at left.

antigens. Other types of controls are required to show the specificity of the antibodies. For both light- and electron-microscopic studies, 2 types of controls were always performed. The first was to process some sections of the tissue without primary antibody but with the secondary antibody. This allowed us to determine if the secondary antibodies bound nonspecifically to the tissue. We found no binding of secondary antibodies, either fluorescein (Fig. 1), colloidal gold, or HRP labeled, in sections incubated only with secondary antibodies. The second type of control was to process adjacent sections with monoclonal antibodies with different specificities. We routinely use antibodies that bind to different glial antigens (Lemmon, 1985, 1986a), different photoreceptor antigens (Lemmon, 1986b), and N-CAM (antibody 1A6) (Lemmon et al., 1982; Rutishauser, 1984). By comparing sections that were incubated under identical conditions but with different antibodies, we were able to evaluate whether a given monoclonal antibody showed selectivity for a certain type of cell.

In some embryos, both eyes were electrolytically lesioned on E3 to destroy the developing eye buds, thereby preventing the axons of retinal ganglion cells from reaching the brain.

\section{Antigen purification}

The 1A6 (anti-N-CAM) and 8D9 antibodies used to prepare affinity columns were purified from ascites fluid by ammonium sulfate precipitation and DEAE Affi-Gel-Blue chromatography (Bruck et al., 1982). The antibodies were linked to Bio-Rad Affi-Gel 10. E19 chick brains were homogenized in $0.32 \mathrm{M}$ sucrose, TBS, $2 \mathrm{~mm}$ EDTA, $1 \mu \mathrm{g} / \mathrm{ml}$ leupeptin, $10 \mu \mathrm{g} / \mathrm{mI}$ aprotinin, $50 \mu \mathrm{g} / \mathrm{ml}$ soybean trypsin inhibitor, and 20 mM phenylmethyl-sulfonyl fluoride. The homogenate was layered on a sucrose gradient (Whittaker et al., 1964), and the plasma membrane fraction was collected. The membrane fraction was pelleted and then solubilizd in $1 \%$ Triton X-100/TBS. After removing insoluble material by centrifugation at $20,000 \times g$ av. for $30 \mathrm{~min}$, the soluble material was run over a $0.5 \mathrm{ml}$ affinity column. After washing the column to remove nonspecifically bound material, the antigen was eluted with $0.1 \mathrm{M}$ diethylamine, $\mathrm{pH} 11.5,1 \%$ Triton X-100. Antisera were produced by immunizing rabbits using the purified 8D9 and 1A6 antigens in Freund's adjuvant.

\section{Western blot analysis of antigens and antibodies}

Triton X-100 soluble membrane proteins prepared as above were boiled in sample buffer and run on a 5-15\% gradient SDS-PAGE (Hames and Rickwood, 1981). After electrophoresis, the proteins were transferred to nitrocellulose paper (Towbin and Gordon, 1984). The nitrocellulose paper was blocked with PBS $/ 10 \%$ HS and cut into strips. The strips were incubated overnight at $4^{\circ} \mathrm{C}$ with rabbit primary antibodies diluted $1: 1000$ in PBS $/ 10 \%$ HS. The strips were then washed with PBS, $0.1 \%$ Tween 20. The Vectastain ABC system and 4-chloro-1-naphthol were used to visualize the location of the primary antibody. As a control, some strips were incubated only with the Vectastain secondary antibodies and $\mathrm{ABC}$ solution to check for nonspecific binding of the secondary antibody. Dot-blot analysis (Towbin and Gordon, 1984) of the $8 \mathrm{D} 9$ antigen was conducted in a similar fashion using polyclonal antibodies against L1 (a kind gift from F. Rathjen and U. Rutishauser, 1984) and N-CAM.

\section{Cell culture studies}

Retinal explants were prepared using E6 retinas grown on collagencoated dishes (Halfter et al., 1981). Live explants were incubated with antibody $8 \mathrm{D} 9$ for $30 \mathrm{~min}$ at $37^{\circ} \mathrm{C}$, then washed with PBS and fixed with $2 \%$ paraformaldehyde, $0.01 \%$ glutaraldehyde, $0.1 \mathrm{M}$ phosphate buffer. The explants were then incubated with a fluorescein-labeled rabbit antimouse-IgG (Cappel Labs) and washed before being examined with an epifluorescence microscope.

\section{Results}

In 2 different fusions using chick optic nerve as immunogen a total of 23 different hybridomas was obtained that appear to bind to the same antigen. One antibody, 8D9, was selected for detailed analysis. Upon examination of E14 retina it was found that the optic fiber layer (OFL) was intensely stained by antibody 8D9 (Fig. 1). There was some faint staining in the inner plexiform layer (IPL), and no apparent staining in other parts of the retina. At this time it is not known if the staining in the IPL is 


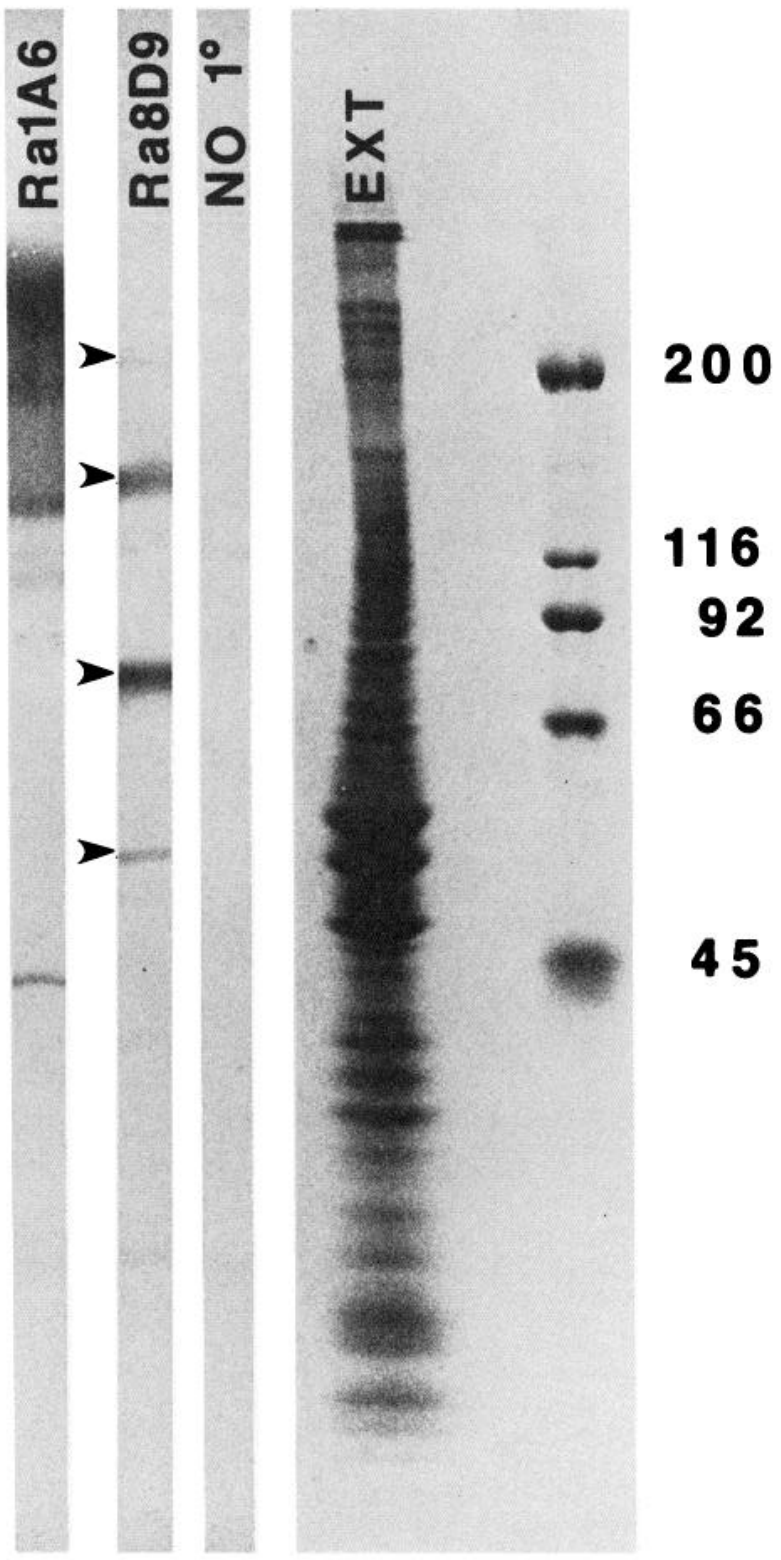

Figure 4. Western blot of Triton X-100 extract of E19 chick brain membranes using rabbit antisera. Ra1A6 (rabbit anti-1A6), Strip incubated with a 1:1000 dilution of antiserum from a rabbit immunized with affinity purified 1 A6 antigen. Ra8D9 (rabbit anti-8D9), Strip incubated with a 1:1000 dilution of antiserum from a rabbit immunized with affinity-purified 8D9 antigen. No $1^{\circ}$. Strip incubated only with the Vectastain anti-rabbit-IgG and $\mathrm{ABC}$ solution. EXT, Coomassie blue stain of membrane extract. Molecular weights indicated at right.

due to staining of ganglion cell dendrites or the processes of some other cell type such as amacrine cells. The 8D9 antigen was present in the OFL uniformly throughout the retina with no apparent differences in different retinal quadrants. EM immunohistochemical studies using both HRP and colloidal gold indicated that the antigen was present on the axons of retinal ganglion cells, but not their somas, or on the end feet of Muller cells (Fig. 2). This is in contrast to antibodies to N-CAM, which stained ganglion cell somas, and antibodies to Muller cells, which stained end feet in tissue prepared in parallel with the retina stained with $8 \mathrm{D} 9$ antibodies (data not shown). In addition, the colloidal gold studies indicated that the $8 \mathrm{D} 9$ antigen is on the external surface of the axons. It must be noted that in addition to staining axons of retinal ganglion cells, these antibodies ap-

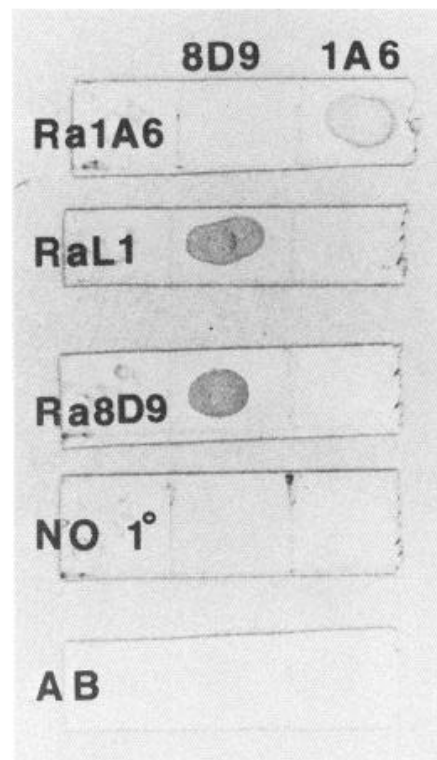

Figure 5. Dot-blot analysis of $1 \mathrm{~A} 6$ and $8 \mathrm{D} 9$ antigens. One microliter of both 8D9 antigen (left-hand column) and 1A6 antigen (right-hand column) was incubated with 1:1000 dilutions of primary antibodies. Ra1A6 antiserum bound to the 1A6 antigen but not the 8D9 antigen. The RaL1 (rabbit anti-L1) antiserum and Ra8D9 both bound to the $8 \mathrm{D} 9$ antigen but not the $1 \mathrm{~A} 6$ antigen. The no primary $\left(\mathrm{No} 1^{\circ}\right)$ control showed no stain. A strip stained with amido black $(A B)$ indicated the small amount of protein present on the strips.

pear to stain axons in many areas of the chick CNS and PNS. The 8D9 antibody was tested on retinas from a number of different species, including monkey, rat, quail, turtle, and frog and was found to bind only to chick retina.

\section{Characterization of the antigen}

A series of immunochemical studies was performed to characterize the cell-surface antigen involved. Attempts to identify the antigen using Western blots failed, indicating that the 8D9 antibody recognizes a determinant that is destroyed by SDSPAGE. Therefore, an affinity column was prepared using 8D9 antibodies. As a control, a second column was made using an antibody 1A6, which binds to N-CAM (Lemmon et al., 1982; Rutishauser, 1984). Plasma membranes were prepared using sucrose gradients. The membranes were solubilized in Triton $\mathrm{X}-100$ and insoluble material was removed by centrifugation. The supernatant was run through the affinity columns. After washing the column, bound material was eluted with diethylamine, $\mathrm{pH} 11.5$, and the eluted fractions were analyzed with SDS-PAGE. Figure 3 shows the material eluted from the 2 different columns. The eluate from the 8D9 column contained 4 prominent bands with molecular weights of approximately $190,135,83$, and $66 \mathrm{kDa}$, as well as some other minor bands. It is possible that some of these minor bands are due to copurification of these molecules via binding to the 8D9 antigen. Further experiments will be required to determine whether these bands are due to breakdown of the $8 \mathrm{D} 9$ antigen or represent distinct molecules. The material eluted from the 8D9 antibody column was different from the N-CAM affinity column, which had a broadly migrating band ranging in molecular weights from about 200 to $140 \mathrm{kDa}$. An important technical observation from these experiments was that while N-CAM appeared relatively insensitive to endogenous proteases during membrane purification, the $8 \mathrm{D} 9$ antigen was extremely sensitive to proteolytic cleavage and required several different protease inhibitors (see Materials and Methods) to prevent total degradation. 

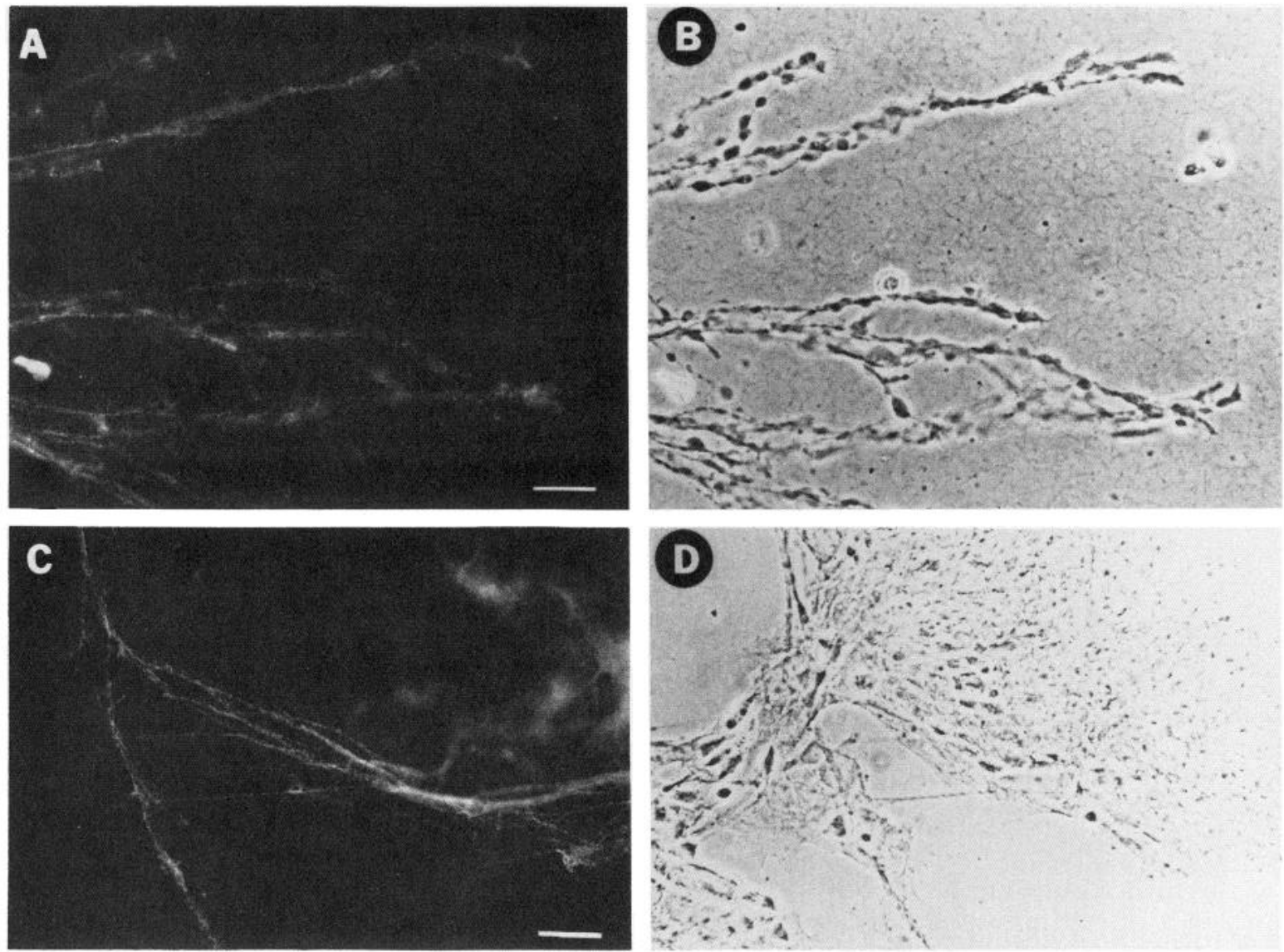

Figure 6. Monoclonal antibody 8D9 staining of retinal explants in culture. $A$ and $B$, Stain of live neurites with staining present to their tips. Scale bar, $10 \mu \mathrm{m}$. $C$ and $D$, Stain of live explant showing stain of neurites but not cell bodies. Scale bar, $30 \mu \mathrm{m}$.

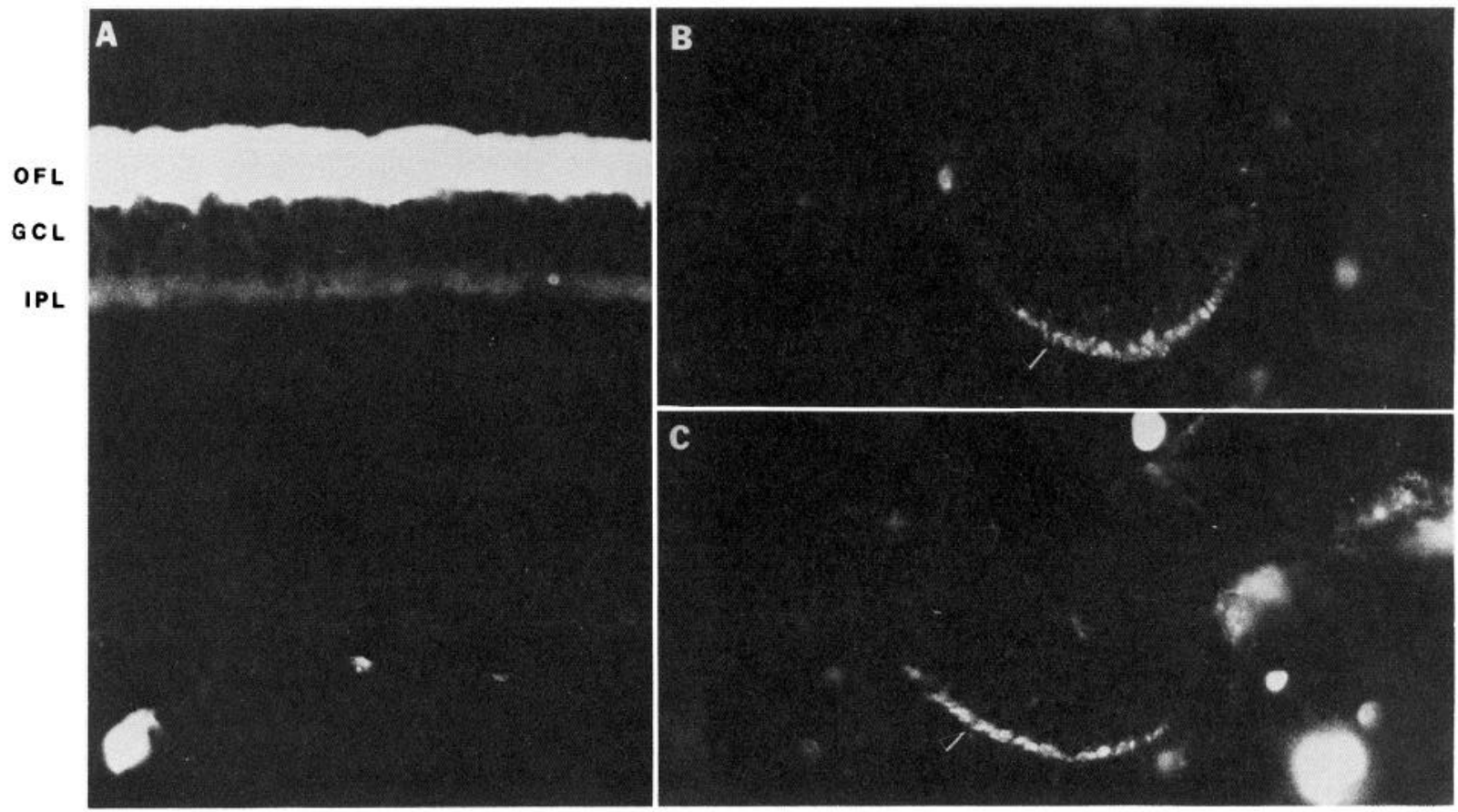

Figure 7. Antibody 8D9 staining of chick visual pathway. $A$, E8 retina shows intense staining of the optic fiber layer (OFL) with some faint staining in the developing inner plexiform layer $(I P L)$. B, E4 optic stalk showing stained axons (arrowhead) at ventral margin of stalk. $C$, E4 optic chiasm with stained axons (arrowhead). 

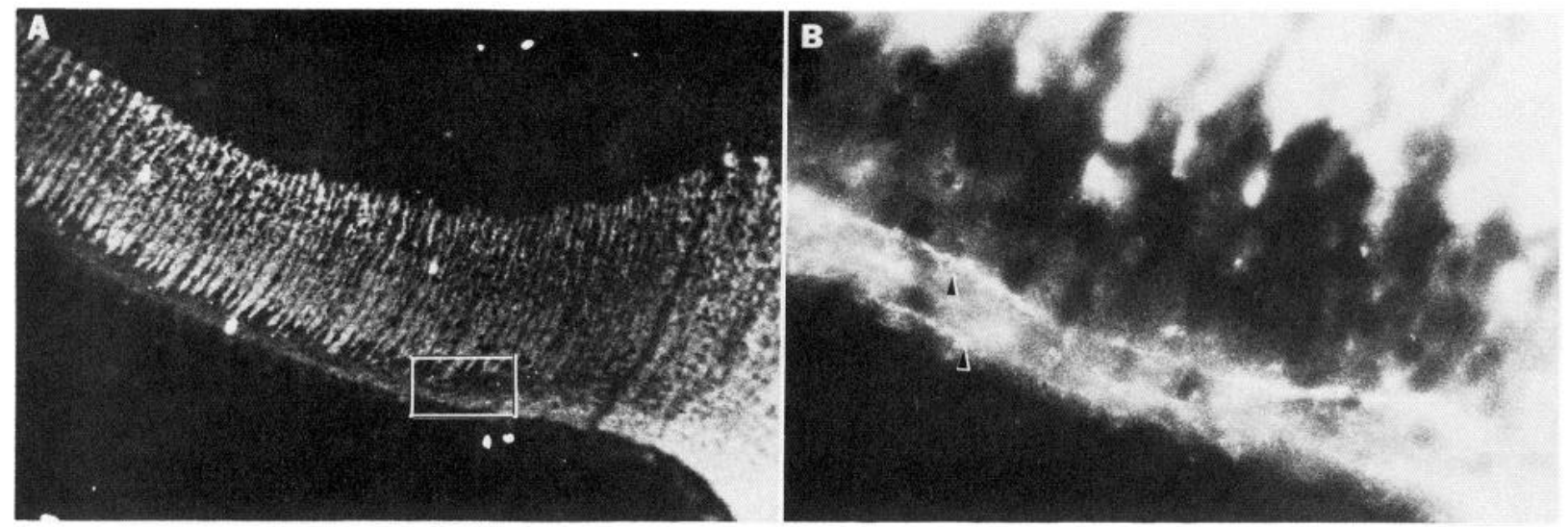

Figure 8. Antibody 8D9 staining of E6 tectum. A, At the rostroventral margin of the tectum, axons are seen coursing over the tectal surface. The ventricle is located at the top of the photo. Original magnification, $\times 250 . B$, Higher magnification of the field delineated by the box in $A$ demonstrates individual axons (arrowheads) passing near cells in the superficial part of the tectum. Original magnification, $\times 650$.

Antigen eluted from the 8D9 affinity column was used to produce a polyclonal antiserum in a rabbit, as was the material from the N-CAM affinity column. Both of these antisera gave the expected staining patterns when tested on retina (Fig. 1) at a dilution of $1: 1000$. When the antisera were tested on Western blots of chick brain plasma membrane, the rabbit anti-8D9 antigen bound to prominent bands of about 190, 135, 83, and $50 \mathrm{kDa}$, while the rabbit anti-N-CAM bound to a smear from about 200 to $130 \mathrm{kDa}$ (Fig. 4).

In order to establish a relationship between the 8D9 antigen and the L1 molecule dot-blot assays were conducted. Purified 8D9 antigen and purified N-CAM were spotted on nitrocellulose paper, and the strips were tested with our rabbit antisera against $8 \mathrm{D} 9$ and N-CAM and a rabbit antiserum against mouse-L1 obtained from F. Rathjen and U. Rutishauser (1984). The anti$\mathrm{L} 1$ antiserum gave a positive reaction with the 8D9 antigen but not the N-CAM, indicating that the 8D9 antigen is immunologically related to mouse-L1 (Fig. 5).
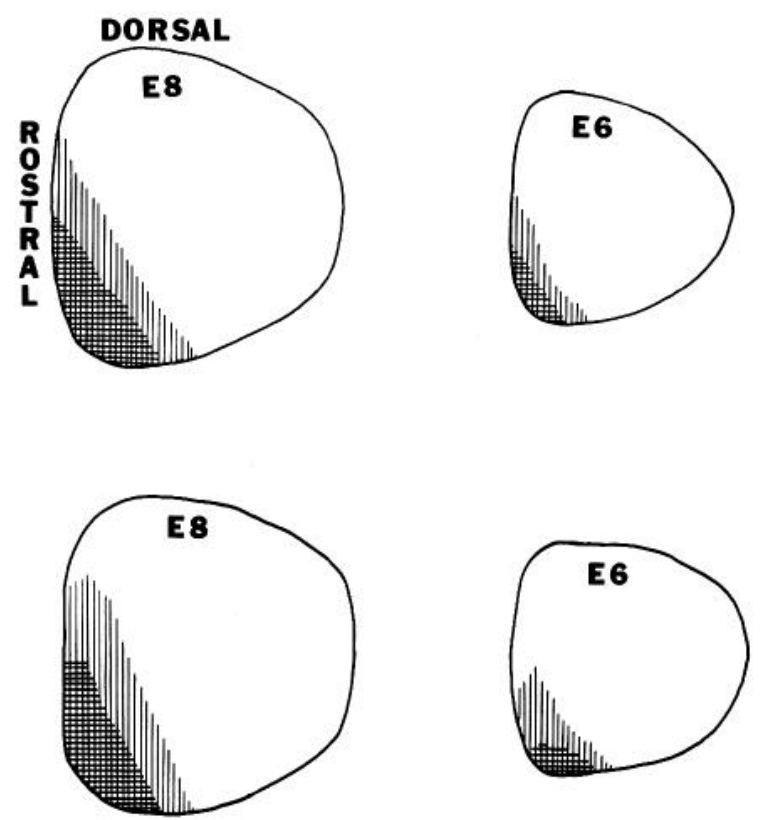

Figure 9. Reconstruction of the distribution of the retinal axons on the tectum of 2 different E6 and E8 embryos. Vertical lines indicate the location of axons in the stratum opticum of the tectum; horizontal lines indicate axons in subjacent cellular layers of tectum.

\section{In vitro experiments}

In order to confirm that the $8 \mathrm{D} 9$ antigen was located on the cell surface, in vitro experiments were performed. E6 retinal explants were cultured on collagen, and neurites were allowed to grow out from the explants for $24 \mathrm{hr}$. Live cultures were stained with 8D9 monoclonal antibodies (see Materials and Methods). When the neurites were examined with phase fluorescence microscopy, it was found that the antibodies bound to the neurites all the way to their tips, indicating that the antigen is also located on growth cones in culture (Fig. 6). Within the explants, stained axon bundles were observed, while cell bodies appeared to be devoid of staining.

\section{Developmental studies}

The appearance of axons that could be stained with monoclonal antibody 8D9 in the primary optic pathways was studied in embryos between E4 and E8. At all ages, retinal staining was concentrated in the OFL with some faint staining in the IPL. At E4, labeled axons were identified in the ventral margin of the optic stalk, in the chiasm, and just entering into the optic tract (Fig. 7). By E6 the first staining of axons in the stratum opticum of the tectum was observed at its rostroventral margin (Fig. 8). At this age, some axons penetrated below stratum opticum into layer i (see LaVail and Cowan, 1971, for nomenclature of tectal layers during development). During E7 and E8 there was a continual advance of axons over the surface of the tectum. While most of the staining was in layer iii, the cell sparse zone subjacent to the stratum opticum, some staining was also present in the deeper cell-rich zone (layer ii). The staining in layer ii appears to develop slightly after the appearance of staining in the superficial layers.

Reconstructions of the pattern of 8D9-labeled axons invading the superficial tectum were made from serial sections of tecta from E6 and E8 embryos (Fig. 9). These reconstructions show axons entering the rostroventral margin of the tectum on E6 and filling much of the rostral tectum by E8. It was also apparent that axons began penetrating tectal layers below the stratum opticum in the rostroventral pole of the tectum. This penetration started almost as soon as axons arrived in the tectum. For any given area of the tectum, axons penetrated below the tectal surface just behind the advancing front of axons on the surface.

\section{Axon staining in embryos without eyes}

Since the 8D9 antigen is present on axons from cells in other regions of the CNS, in addition to axons of retinal ganglion cells, it was necessary to determine whether the staining in the su- 


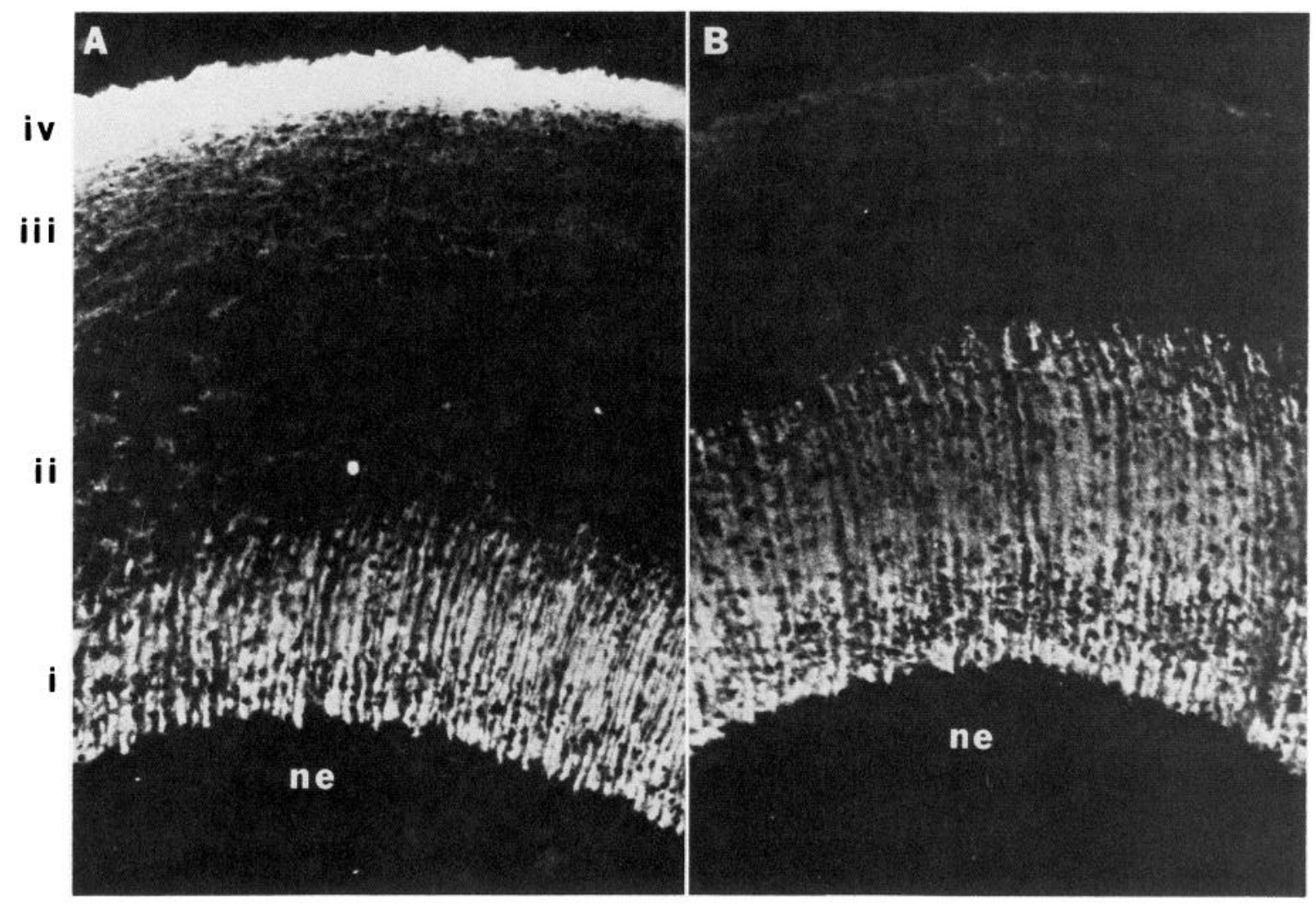

Figure 10. Antibody 8D9 staining of $\mathrm{E} 8$ tectum. A, Normal tectum with intense staining in layer iv (stratum opticum) and significant staining present in layer iii. The neuroepithelium (ne) adjacent to the ventricle is negative. $B$, Tectum from an embryo with a bilateral enucleation has almost no staining in layers ii and iii, and layer iv is absent. Original magnification, $\times 250$.

perficial tectal layers, as described above, was of retinal origin. Embryos that had both eyes destroyed prior to the appearance of retinal axons were processed as above. In these embryos the staining in the superficial tectal layers was completely absent (E8, normal and lesioned; Fig. 10). There was a considerable amount of staining in the cell-sparse zone adjacent to the ventricular neuroepithelium (layer i) in the tecta of these embryos, comparable to that seen in normal embryos.

\section{Discussion}

Based on the similarities of their staining patterns in the retina, the molecular weights of the proteins eluted from affinity columns, and cross-reactivity using dot-blots, we believe that antibody $8 \mathrm{D} 9$ binds to a molecule in chick that is related to the mouse L1 antigen. Anti-L1 antibodies have been found to bind antigens in the mouse brain with molecular weights of about 200 and $140 \mathrm{kDa}$ (Rathjen and Schachner, 1984). L1 has been shown to be involved in neuronal cell adhesion (Lindner et al., 1983; Rathjen and Schachner, 1984). The 8D9 antigen also has a similar distribution in the retina to a molecule referred to as $\mathrm{Ng}$-CAM (Grumet and Edelman, 1984), in that they are both concentrated on axons of ganglion cells with some faint staining in the IPL (Thiery et al., 1985). In addition, Ng-CAM and the 8D9 antigen have similar molecular weights (Grumet et al., 1984). The Ng-CAM molecule was first described in a series of experiments studying neuron-glia (heterotypic) adhesion in the chick (Grumet et al., 1983). It has subsequently also been found to be involved in neuron-neuron (homotypic) adhesion in the chick (Grumet et al., 1984). Grumet and associates have proposed that $\mathrm{Ng}$-CAM binds through a heterophilic binding process, with $\mathrm{Ng}-\mathrm{CAM}$ not binding to itself but rather to a different molecule, although the ligand for $\mathrm{Ng}$-CAM has not been isolated at this time. This is in contrast to N-CAM, which is thought to bind via a homophilic mechanism, i.e., one N-CAM molecule binding to another N-CAM molecule (Hoffman and Edelman, 1983). While we do not have direct evidence that the 8D9 antigen is related to $\mathrm{Ng}-\mathrm{CAM}$, it seems reasonable that this is the case.

Using monoclonal antibodies against the 8D9 antigen, we were able to follow the distribution of retinal axons in the developing tectum. Axons entered the rostroventral tectum on E6 and ran in the stratum opticum. On E7 and E8 the distribution of the axons expanded over much of the rostral tectum. Since in embryos without eyes this staining was abolished, it seems likely that these are retinal axons. This pattern of retinal axon ingrowth into the tectum is the same as that observed by labeling the retinal projection with anterograde tracers (Crossland et al., 1975; McLoon, 1985) or with silver stains (Rager and von Oeynhausen, 1979). It appears that axons begin to penetrate tectal layers below the stratum opticum almost as soon as they enter the tectum. This is in agreement with the results obtained by anterogradely labeling the retinal projection with HRP (McLoon, 1985).

It is not yet clear what the role of this L1-like cell-surface molecule is in visual system development. It might promote axon fasciculation in the OFL of the retina, the optic nerve and tract, and in the stratum opticum of the tectum using a nervenerve adhesion mechanism similar to that proposed for L1 (Rathjen and Schachner, 1984). It might also mediate a nerveglia adhesion process similar to that proposed for Ng-CAM (Grumet and Edelman, 1984) in the developing optic pathway, serving to guide axons along the neuroepithelia of the optic stalk. A third possibility is that it may provide some more subtle cue in axon guidance that influences target selection in the tectum. 
If this last possibility were the case, one would predict that the concentration of the antigen would vary in different parts of the retina. However, this seems unlikely since our immunohistochemical examination of the visual pathway revealed no obvious gradients of antigen concentration from dorsal to ventral retina or nasal to temporal retina.

The localization of the 8D9 antigen on the axons of ganglion cells appears to be consistent with a function of axon fasciculation. In this regard, it is worth noting that ongoing experiments by Susannah Chang and Jonathan Raper indicate that polyclonal Fab fragments against the 8D9 antigen inhibit neurite outgrowth on neurites. In the retina, optic nerve, and tract, all axons seem to be equally labeled by 8D9 antibodies whether they are adjacent to axons or near glial end-feet. It is not just growth cones and axons adjacent to glia that are labeled by $8 \mathrm{D} 9$ antibodies. As the axons enter the tectum, many of them leave the stratum opticum to penetrate the subjacent cellular layers. This suggests a number of possibilities. For example, the tectal neurons may have a receptor for the 8D9 antigen that would allow them to compete with other axons for adhesion of ingrowing axons, thereby disrupting fasciculation. In order to address this possibility, it will be necessary to identify the ligand(s) for L1 and study its localization. Another interesting possibility is that the extreme protease sensitivity of the 8D9 antigen plays a functional role and that as the axons enter the tectum, the molecule is cleaved, disrupting axon fasciculation and allowing axons to penetrate the cellular layers. The use of monoclonal antibodies to identified fragments of the $\mathrm{L} 1$ molecule might help settle this question.

\section{References}

Adams, J. (1981) Heavy metal intensification of DAB-based HRP reaction product. J. Histochem. Cytochem. 29: 775.

Bruck, C., D. Portctclle, C. Glineur, and A. Bollen (1982) One-step purification of mouse monoclonal antibodies from ascitic fluid by DEAE Affi-Gel Blue chromatography. J. Immunol. Methods 53:313319.

Cole, G. J., D. Schubert, and L. Glaser (1985) Cell-substratum adhesion in chick neural retina depends upon protein-heparan sulfate interactions. J. Cell Biol. 100: 1192-1199.

Crossland, W. J., W. M. Cowan, and L. A. Rodgers (1975) Studies on the development of the chick optic tectum. IV. An autoradiographic study of the development of retino-tectal connections. Brain Res. 91 : $1-23$.

Dunn, B. E., and M. A. Boone (1976) Growth of the chick embryo in vitro. Poult. Sci. 55: 1067-1071.

Grumet, M., and G. M. Edelman (1984) Heterotypic binding between neuronal membrane vesicles and glial cclls is mediated by a specific cell adhesion molecule. J. Cell Biol. 98: 1746-1757.

Grumet, M., U. Rutishauser, and G. Edelman (1983) Neuron-glia adhesion is inhibited by antibodies to neural determinants. Science 222: 60-62.

Grumet, M., S. Hoffman, C.-M. Choung, and G. M. Edelman (1984) Polypeptide components and binding functions of neuron-glia cell adhesion molecules. Proc. Natl. Acad. Sci. USA 81: 7989-7993.

Halfter, W., M. Claviez, and U. Schwarz (1981) Preferential adhesion of tectal membranes to anterior embryonic chick retina neurites. Nature 292: 67-70.

Hamburger, $V$., and $H$. Hamilton (1951) A series of normal stages in the development of the chick embryo. J. Morphol. 88: 49-92.

Hames, B. D., and D. Rickwood, eds. (1981) Gel Electrophoresis of Proteins: 4 Practical Approach, IRL Press, Oxford, UK.

Hatta, K., T. S. Okada, and M. Takeichi (1985) A monoclonal anti- body disrupting calcium-dependent cell-cell adhesion of brain tissues: Possible role of its target antigen in animal pattern formation. Proc. Natl. Acad. Sci. USA 82: 2789-2793.

Hoffman, S., and G. M. Edelman (1983) Kinetics of homophilic binding by embryonic and adult forms of the neural cell adhesion molecule. Proc. Natl. Acad. Sci. USA 80: 5762-5766.

Kohler, G., and C. Milstein (1975) Continuous cultures of fused cells secreting antibodies of predefined specificity. Nature 256: 495-497.

LaVail, J. H., and W. M. Cowan (1971) The development of the chick optic tectum. I. Normal morphology and cytoarchilectonic development. Brain Res. 28: 391-419.

Lemmon, V. (1985) Monoclonal antibodies specific for glia in the chick nervous system. Dev. Brain Res. 23: 111-120.

Lemmon, V. (1986a) The localization of a filamin-like protein in glia of the chick central nervous system. J. Neurosci. 6: 43-51.

Lemmon, V. (1986b) A monoclonal antibody that binds to cones. Invest. Ophthal. Vis. Sci. 27: 831-836.

Lemmon, V., E. B. Starvos, H. E. Perry, and D. I. Gottlieh (1982) A monoclonal antibody that binds to the surface of chick brain cells and myotubes: Cell selectivity and properties of the antigen. Dev. Brain Res. 11: 191-197.

Lindner, J., F. G. Rathjen, and M. Schachner (1983) L1 mono- and polyclonal antibodies modify cell migration in early postnatal mouse cerebellum. Nature 305: 427-430.

McClay, D. R. (1984) Cell recognition of embryonic chick neural retina: Direct interference with monoclonal antibodies. J. Cell Biol. 99: 116a.

McClay, D. R., and A. A. Moscona (1974) Purification of the specific cell-aggregating factor from embryonic neural retina cells. Exp. Cell Res. 87: 438-442.

McLean, I. W., and P. K. Nakane (1974) Periodate-lysine paraformaldehyde fixative: A new fixative for immunoelectronmicroscopy. $J$. Histochem. Cytochem. 22: 1077-1083.

McLoon, S. C. (1985) Evidence for shifting connections during development of the chick retinotectal projection. J. Neurosci. 5: 2570 2580.

Rager, G., and B. von Oeynhausen (1979) Ingrowth and ramification of retinal fibers in the developing optic tectum of the chick embryo. Exp. Brain Res. 35: 213-227.

Rathjen, F. G., and U. Rutishauser (1984) Comparison of two cell surface molecules involved in neural cell adhesion. EMBO J. 3: 461465.

Rathjen, F. G., and M. Schachner (1984) Immunocytological and biochemical characterization of a new neuronal cell surface component ( $\mathrm{L} 1$ antigen) which is involved in cell adhesion. EMBO J. 3: 110.

Rutishauser, U. (1984) Developmental biology of a neural cell adhesion molecule. Nature 310: 549-554.

Thiery, J.-P., R. Brackenbury, U. Rutishauser, and G. M. Edelman (1977) Adhesion among neural cells of the chick embryo. II. Purification and characterization of a cell adhesion molecule from neural retina. J. Biol. Chem. 252: 6841-6845.

Thiery, J.-P., A. Delouvee, M. Grumet, and G. M. Edelman (1985) Initial appearance and regional distribution of the neuron-glia cell adhesion molecule in the chick embryo. J. Cell Biol. 100: 442-456.

Towbin, H., and J. Gordon (1984) Immunoblotting and dot immunoblotting-current status and outlook. J. Immunol. Methods 72: 313-340.

Trisler, G. D., M. D. Schneider, J. R. Moskal, and M. Nirenberg (1981) A gradient of molecules in avian retina witih dorsoventral polarity. In Monoclonal Antibodies to Neural Antigens, R. McKay, M. C. Raff, and L. F. Reichardt, eds., Cold Spring Harbor Lab., Cold Spring Harbor, NY.

Whittaker, V. P., I. A. Michaelson, and R. J. A. Kirkland (1964) The separation of synaptic vesicles from nerve-ending particles ('synaptosomes'). Biochem. J. 90: 293-303. 